\title{
Sigmoid Perforation by a Migrated Plastic Biliary Stent
}

\author{
Pedro Marcos ${ }^{a}$ Gustavo Capelão $^{b}$ Catarina Atalaia-Martins $^{a}$ Paulo Clara ${ }^{b}$ \\ Liliana Eliseu $^{\text {a Helena Vasconcelos }}{ }^{a}$ \\ ${ }^{a}$ Gastroenterology Department, Centro Hospitalar de Leiria, Leiria, Portugal; ${ }^{b}$ General Surgery Department, \\ Centro Hospitalar de Leiria, Leiria, Portugal
}

Keywords

Intestinal perforation - Endoscopic retrograde

cholangiopancreatography . Stent

\section{Perfuração da sigmoide por uma prótese biliar plástica migrada}

\section{Palavras Chave}

Perfuração intestinal · Colangiopancreatografia retrograda endoscópica · Prótese

A 65-year-old female with a previous history of endoscopic retrograde cholangiopancreatography (ERCP) with stone extraction and placement of a straight biliary plastic stent (5 $\mathrm{cm}$ long and $10 \mathrm{Fr}$ in diameter) due to residual choledocholithiasis presented with spontaneous distal migration of the stent in the scheduled ERCP 6 weeks later. The residual stones were removed. However, an abdominal X-ray to confirm the passage of the stent was not carried out. A subsequent laparoscopic cholecystectomy was uneventfully performed. Asymptomatic, 1 year later, the patient underwent a screening colonoscopy that revealed a foreign body suggestive of a plastic biliary stent, impacted in the sigmoid colon, in an area of diverticula (Fig. 1). The computed tomography showed a tubular structure compatible with the biliary stent perforating the sigmoid colon with both tips (Fig. 2). The CT scan did not reveal additional complications, and the patient remained asymptomatic. After multidisciplinary discussion, a surgical approach was proposed. The patient underwent an uneventful laparoscopic surgery with successful stent removal and closure of the perforations (Fig. 3).

Overall, biliary plastic stent migration (proximal and distal) occurs in $5-10 \%$ of the patients. Distal migration occurs in $4 \%$ of the cases and is more common in benign than malignant biliary conditions and when a single straight stent is placed [1].

\begin{tabular}{ll}
\hline KARGER & $\begin{array}{l}\text { (c) } 2019 \text { Sociedade Portuguesa de Gastrenterologia } \\
\text { Published by S. Karger AG, Basel }\end{array}$ \\
karger@karger.com & \\
www.karger.com/pjg & $\begin{array}{l}\text { This article is licensed under the Creative Commons Attribution- } \\
\text { NonCommercial-NoDerivatives 4.0 International License (CC BY- } \\
\text { NC-ND) (http://www.karger.com/Services/OpenAccessLicense). } \\
\text { Usage and distribution for commercial purposes as well as any dis- } \\
\text { tribution of modified material requires written permission. }\end{array}$
\end{tabular}


Fig. 1. Endoscopic view of the impacted biliary stent in the sigmoid colon.
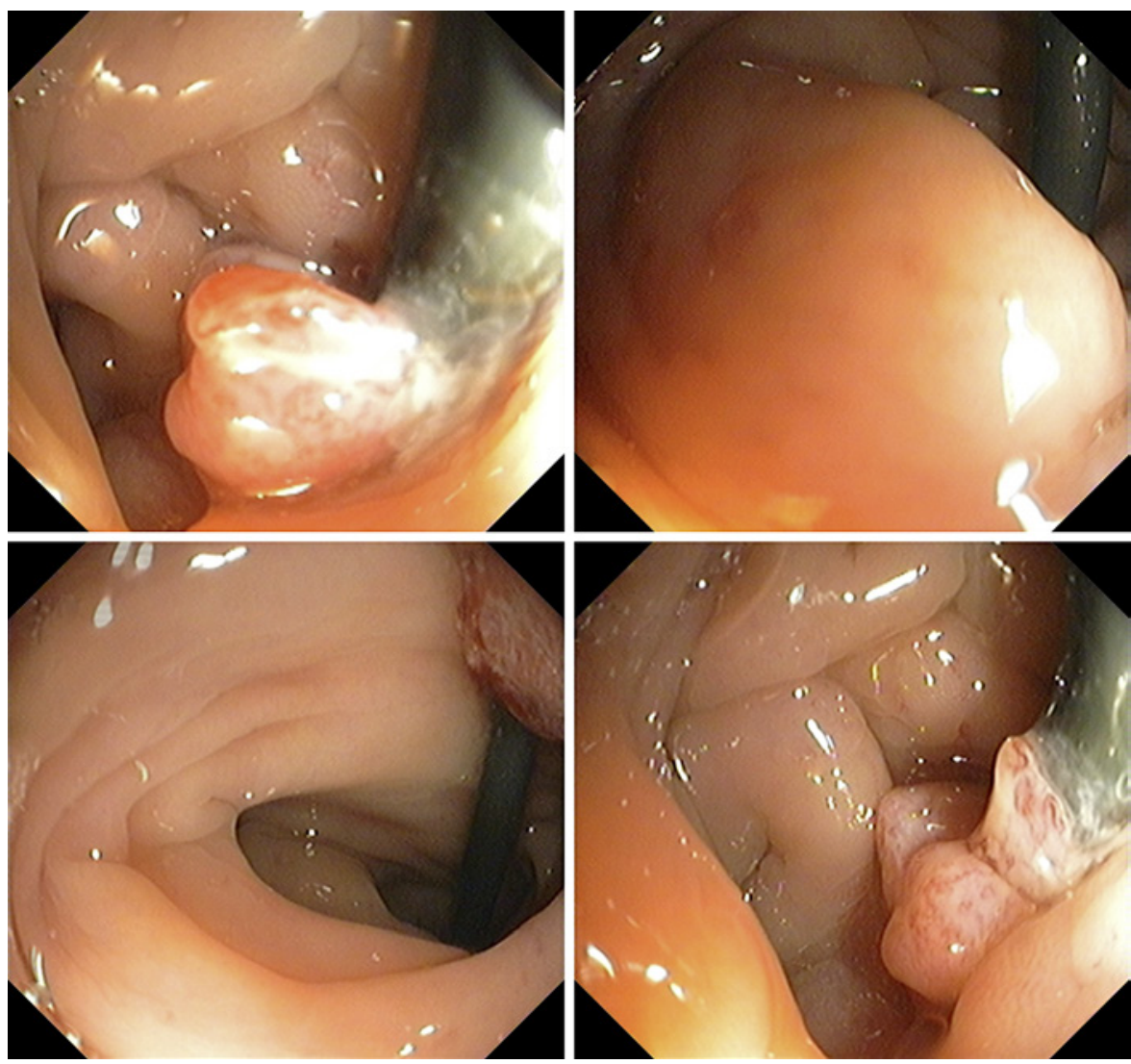

Despite being generally a benign process, in rare instances, distally migrated plastic stents can fail to pass, become trapped in the small bowel or colon (mainly, in the duodenum, distal ileum, or sigmoid colon) and cause serious injuries such as bowel perforations $[2,3]$.

Colonic perforations by migrated biliary plastic stents have been rarely described [2-4]. The sigmoid has been the colon segment most commonly involved. Diverticulosis, abdominal hernias, previous surgeries/adhesions, and the characteristics of the plastic stent itself (straight and long) are risk factors for this complication [2-5]. In selected cases, stent removal with closure of the perforation can be done endoscopically [5]. In this case, as both stent tips were perforating the colonic wall, we preferred the surgical approach.

Endoscopists placing biliary plastic stents should always ensure that there is a plan for its retrieval. The ideal interval for scheduled removal depends on the pathology but should not exceed 3-4 months. Nevertheless, early stent removal can be prudent when there are risk factors for stent migration or for migration-related complications [4]. Whenever possible, the use of double pigtail biliary stents should be considered, since these are associated with less secondary complications than migrated straight stents [2].

Patients with distally migrated stent(s), even if asymptomatic, should receive an abdominopelvic X-ray, during the ERCP or after, to confirm the passage of the stent or its bowel retention. Asymptomatic patients with retained distally migrated stents should receive regular clinical and imaging evaluation (X-ray) to check the stent progression. Once the stent seems to be in the colon, endoscopic retrieval should be weighted, mainly in cases with risk factors for stent impaction/perforation. Patients with retained stents in the same topography during consecutive X-rays or who develop alarm signs (such as abdominal pain, fever, or hematochezia) should receive immediate evaluation because these signs could suggest stent impaction and associated complications. 

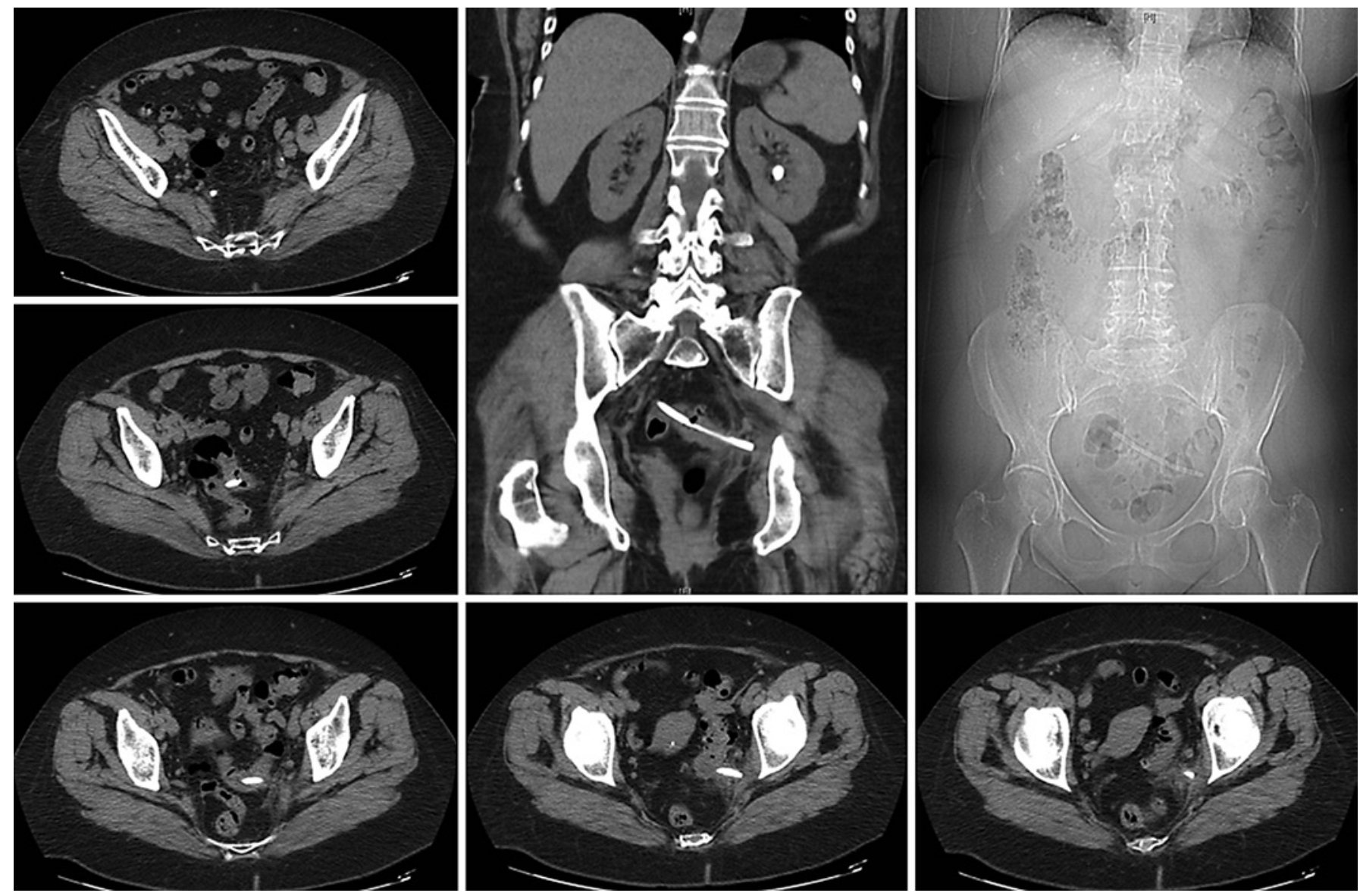

Fig. 2. Abdominopelvic computed tomography scan showing a straight biliary stent perforating the sigmoid colon with both tips, one of them extending retroperitoneally to the internal obturator muscle.

\section{Statement of Ethics}

Informed consent was obtained from the patient for the case publication.

\section{Disclosure Statement}

The authors have no conflicts of interest to declare.

\section{Funding Sources}

The authors have no funding sources to declare.

\section{Author Contributions}

Dr. Pedro Marcos wrote the manuscript and is the article guarantor. Dr. Gustavo Capelão, Dr. Catarina Atalaia-Martins, and Dr. Paulo Clara revised the manuscript. Dr. Liliana Eliseu and Dr. Helena Vasconcelos revised the manuscript and approved the final version. 

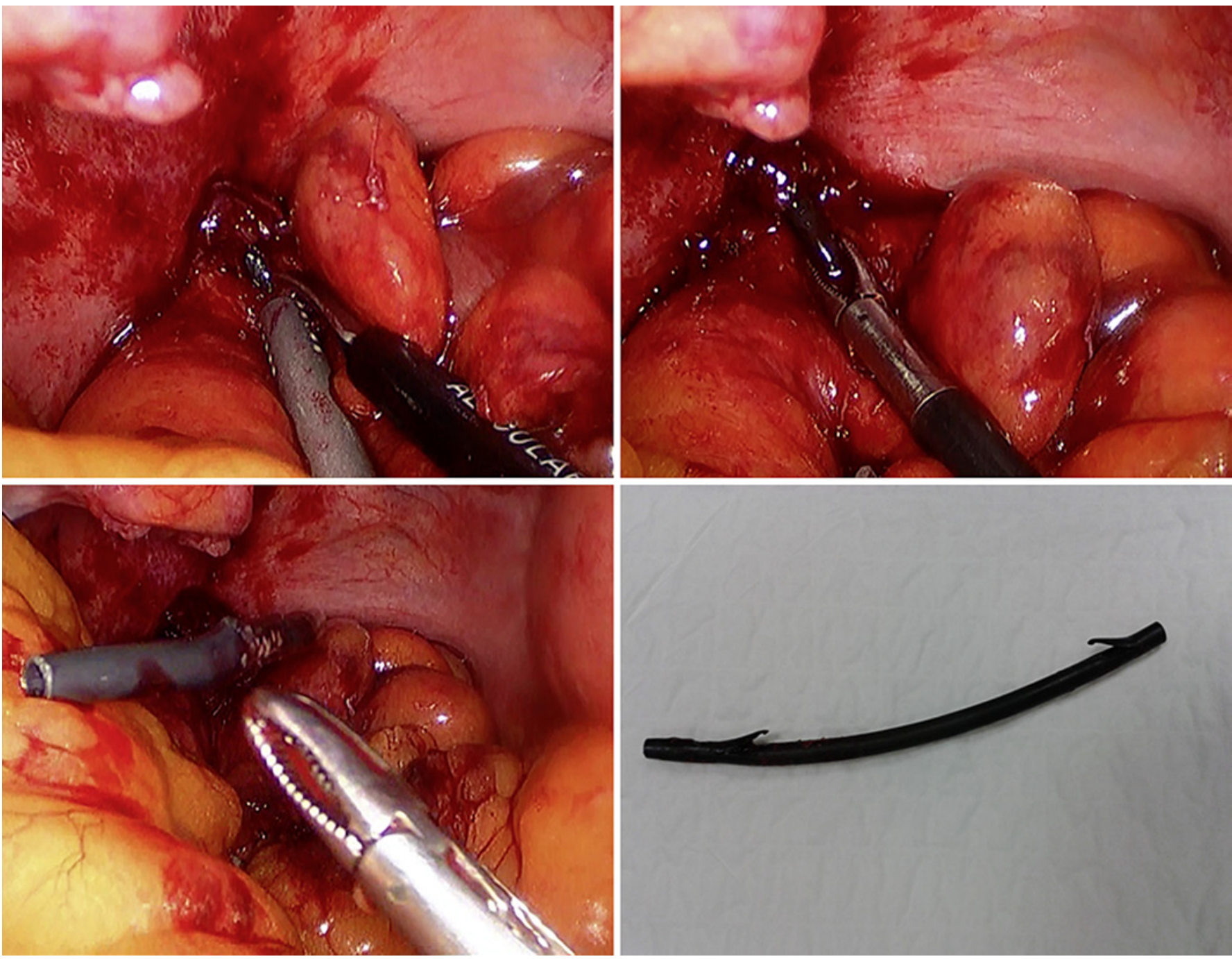

Fig. 3. Laparoscopic view of the stent perforating the colon during its removal and the retrieved stent.

References
1 Arhan $\mathrm{M}$, Odemiş $\mathrm{B}$, Parlak E, Ertuğrul I, Başar O. Migration of biliary plastic stents: experience of a tertiary center. Surg Endosc. 2009 Apr;23(4):769-75.

2 Bagul A, Pollard C, Dennison AR. A review of problems following insertion of biliary stents illustrated by an unusual complication. Ann R Coll Surg Engl. 2010 May;92(4):W27-31.

3 Namdar T, Raffel AM, Topp SA, Namdar L, Alldinger I, Schmitt M, et al. Complications and treatment of migrated biliary endoprostheses: a review of the literature. World J Gastroenterol. 2007 Oct;13(40):5397-9.
4 Riccardi M, Deters K, Jabbar F. Sigmoid Diverticulitis and Perforation Secondary to Biliary Stent Migration. Case Rep Surg. 2019 May;2019:2549170.

5 Alcaide N, Lorenzo-Pelayo S, HerranzBachiller MT, de la Serna- Higuera C, Barrio J, Perez-Miranda M. Sigmoid perforation caused by a migrated biliary stent and closed with clips. Endoscopy. 2012;44 Suppl 2 UCTN:E274.
Marcos/Capelão/Atalaia-Martins/Clara/ Eliseu/Vasconcelos 